\title{
Patchiness in assemblages of epiphytic macroalgae on Posidonia coriacea at a hierarchy of spatial scales
}

\author{
M. A. Vanderklift ${ }^{*}$, P. S. Lavery \\ Centre for Ecosystem Management, Edith Cowan University, Joondalup Drive, Joondalup, Western Australia 6027 , Australia
}

\begin{abstract}
Epiphytic algae are important contributors to ecological functions in seagrass ecosystems. However, little is known about the spatial scales at which epiphytic algae vary. Such information is vital for elucidating processes that structure assemblages, and for providing information on variability important for designing comparative and experimental studies. In this study, we examined variation in assemblages of epiphytic macroalgae on Posidonia coriaced at a hierarchy of spatial scales. We sampled according to a nested hierarchical design, with samples separated by distances ranging from centimetres to kilometres. The largest differences were associated with samples separated by kilometres. Differences at the scale of hundreds of metres were comparable to differences at the scale of metres, suggesting that patchiness at the scale of metres was the dominant pattern at scales less than a kilometre. Patchiness at the scale of metres may have been related to differences in shoot density. Patchiness at this scale might be an important feature of epiphyte assemblages, and should be considered in designs of studies.
\end{abstract}

KEY WORDS: Epiphyte - Nested sampling design - Patchiness - Seagrass - Species composition Shoot density

\section{INTRODUCTION}

Epiphytic algae grow on other plants, and include groups as diverse as true multicellular algae, diatoms and cyanobacteria (Jernakoff et al. 1996). In seagrass ecosystems, epiphytic algae may contribute substantially to primary and secondary production (Penhale 1977, Fry 1984, Morgan \& Kitting 1984, Klumpp et al. 1992). They are also known to make significant contributions to biogeochemical processes and nutrient cycling, including $\mathrm{CaCO}_{3}$ production (Walker \& Woerkerling 1988, Hegge et al. unpubl.) and nitrogen fixation (Goering \& Parker 1972). However, epiphytic algae may also have deleterious effects on ecological functions in seagrass ecosystems (Jernakoff et al. 1996), including shading their seagrass hosts severely enough to cause death (Cambridge et al. 1986, Silberstein et al. 1986).

\footnotetext{
- Present address: Department of Botany, The University of Western Australia, Nedlands, Western Australia 6907, Australia. E-mail: matvdk@cyllene.uwa.edu.au
}

Despite the integral role epiphytic algae have in seagrass ecosystems, little is known about the spatial scales of patterns in assemblages of epiphytic algae. Knowledge of the spatial scales at which patterns in distributions of organisms occur is valuable in 2 ways (Thrush 1991). Firstly, understanding of patterns (and the grain and extent of patterns: Kotliar \& Wiens 1990) will often yield insight into the processes that structure assemblages. Secondly, some knowledge of the scales at which patterns exist will yield estimates of variability needed for designing comparative and experimental studies (Andrew \& Mapstone 1987).

Recent discussions of how to examine patterns in ecology have involved consideration of hierarchical sampling. Hierarchical sampling is useful as patterns exist at multiple scales, and no single scale of sampling will capture all patterns (Levin 1992). Descriptions of patterns at multiple scales will also aid in discerning factors that are important determinants of assemblage structure (Farnsworth \& Ellison 1996). Most investigations into hierarchical patterns have been univariate 
studjes, in which only 1 variable (usually the density of a species) is tested at a time (although see Hewitt et al. 1998). Less is known of small-scale patchiness in assemblages of taxa - patterns that cannot be easily examined by univariate analyses. Patterns displayed by assemblages of taxa are also likely to be complex, as different organisms may display patchiness at different spatial scales (Kotliar \& Wiens 1990).

Knowledge of the spatial patterns of assemblages of epiphytic algae is useful, as species compositions will strongly influence commonly measured variables such as biomass and production. In addition, there is also some evidence that shifts in species compositions may be used to indicate anthropogenic impacts (e.g Wilmotte \& Demoulin 1988, Coleman \& Burkholder 1994, Lin et al. 1996).

In this study, we used multivariate methods to examine variability in species compositions of assemblages of epiphytic macroalgae (multicellular algae and cyanobacteria) at a nested hierarchy of spatial scales from centimetres to kilometres. The host seagrass species was Posidonia coriacea Kuo \& Cambridge, a southern Australian endemic that grows with a clumping habit in areas of relatively high wave energy (Kuo \& Cambridge 1984). From the results obtained, we speculate on the processes that may be most important in structuring assemblages of epiphytic algae, and comment on the implications for designing studies of these assemblages.

\section{METHODS}

Sample collection. Our study area was located at Success Bank, a relatively shallow (<10 $\mathrm{m}$ deep) sand bank situated adjacent to the coast south of the Swan River estuary in southwestern Australia (Fig 1). We sampled 2 regions of Success Bank, separated by $2 \mathrm{~km}$, during May 1996 (Fig. 1). Within each region we sampled 2 locations separated by a few hundred metres. Thus, the top 2 levels of our spatial hierarchy were region (kilometres apart) and locations within region (hundreds of metres apart).

Wo also cxamined 2 further lovels. Wo examined variability at the scale of metres by collecting 5 sets of samples within each location, with each set of samples separated by 1 to $10 \mathrm{~m}$. Within each set of sampies we estimated variability at the scale of centimetres by col- lecting all samples from within the same quadrat. The quadrat was $50 \times 50 \mathrm{~cm}$, divided into a grid of $10 \times$ $10 \mathrm{~cm}$ subquadrats. Divers deployed the quadrat 5 times, and collected seagrass from 5 randomly selected subquadrats.

There were thus 5 sets of samples for each location, with each set of samples representing a quadrat, and each sample a subquadrat. As much below-ground seagrass material as possible was collected to ensure that shoots remained intact. Samples were placed in plastic bags, with $95 \%$ seawater $/ 5 \%$ formalin.

Sample processing. In the laboratory, the oldest leaf from each seagrass shoot was examined under medium power using a stereo microscope (we selected the oldest leaf as a pilot study had shown that younger leaves generally did not contain additional epiphyte taxa). Epiphyte taxa were identified to species when possible (species of encrusting coralline algae could not be distinguished and were grouped). The presence of each taxa on each leaf was recorded separately. The proportion of shoots within each sample that a taxa occurred on was then calculated. For multivariate analyses, these data were converted to presence/ absence data.

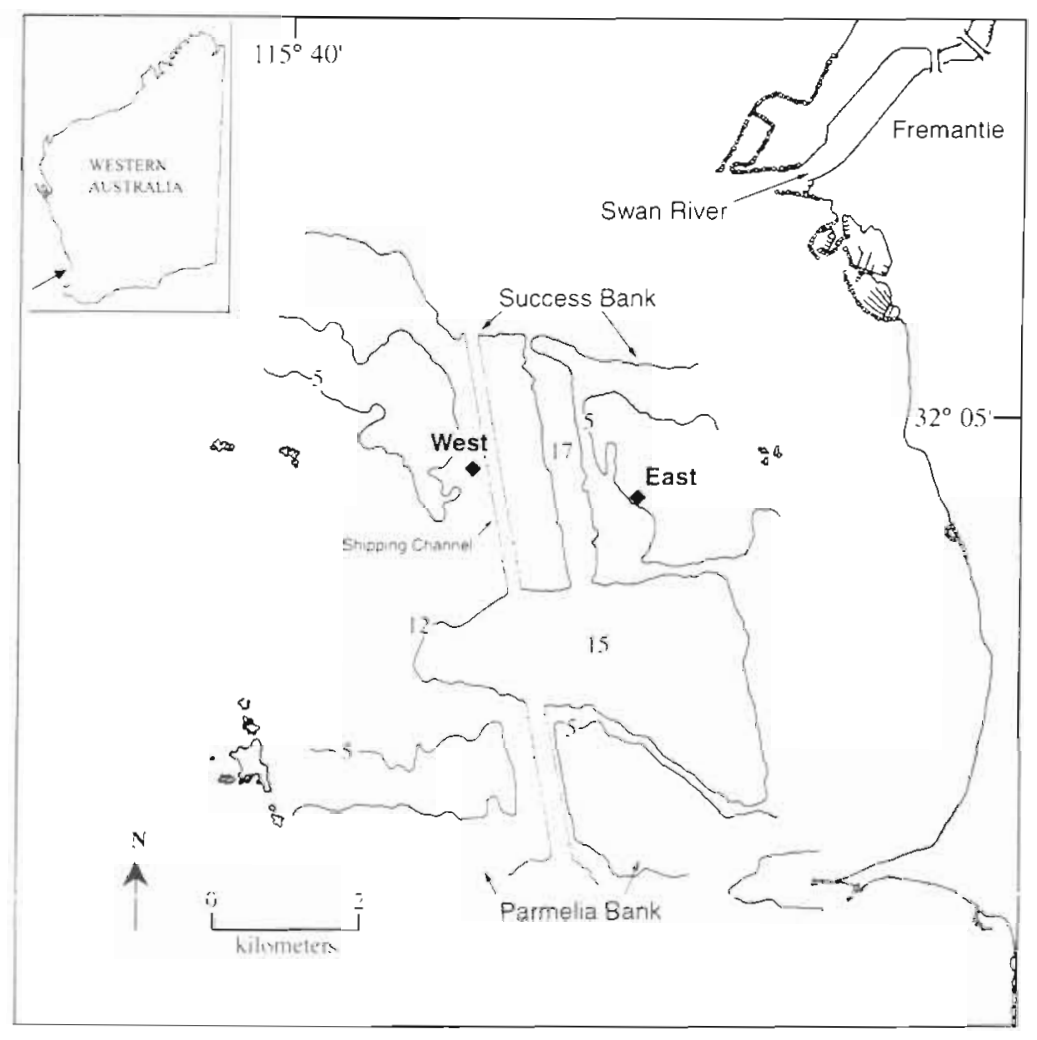

Fig. 1. Map of the study area showing the 2 regions (West and East) of Success Bank at which the study was conducted 
Some of the selected subquadrats fell on bare sand. As there were no epiphytes in these samples, all values were zero. As the statistical software used was unable to handle objects with only zero values, they were excluded from analyses.

Data manipulation. Shoot density in each sample varied, providing varying amounts of area available for epiphyte colonisation. We wished to determine whether spatial patterns were independent of the direct effect of shoot density. To do this, we created 5 datasets (an arbitrarily chosen number) in which the number of shoots in each sample was constrained to 3 . We generated these datasets by randomly selecting 3 shoots sample ${ }^{-1}$. There were some samples in the original data that contained less than 3 shoots, and these were not included in the constrained datasets. Because this meant that the number of samples in the constrained datasets was different to that in the original data, direct statistical comparisons of the 5 constrained datasets with the unconstrained data could not be made. To enable such comparisons, we generated an additional dataset with the same data as the original dataset (i.e. with the number of shoots unconstrained), but excluding samples with $<3$ shoots (this dataset is hereafter called the reduced dataset).

Statistical analyses. Our statistical analyses were focussed on several main questions. Firstly, we examined patterns at different spatial scales, and magnitudes of dissimilarity among spatial scales. This also involved examining macroalgal taxa that contributed to patterns. We then examined whether the patterns observed were maintained when data were manipulated to control shoot density.

To view patterns in the original dataset related to region and location, we constructed a Semi-Strong Hybrid multidimensional scaling ordination (SSH: Belbin 1991), based on Bray-Curtis dissimilarity values (Bray \& Curtis 1957). The ordination was constructed in 2 dimensions, using an ordinal approach for all dissimilarities above zero.

We used ANOSIM to statistically test for differences in species compositions. However, because ANOSIM cannot be used to analyse data with more than 2 factors, we could not include all levels of the spatial hierarchy examined. (Underwood \& Chapman [1998] outline a multivariate technique that can be used to analyse data with more than 2 levels, but the number of replicates required exceeded the number collected in our study.) Separate analyses were therefore conducted for each region, testing for differences between the 2 locations, and among quadrats within locations, using 2-way nested ANOSIM (Clarke 1993). One-way ANOSIM (Clarke \& Green 1988) was used to generate multiple comparison tests to examine which pairs of quadrats were significantly different within each location.
To examine the epiphyte taxa that contributed most to differences between significantly different quadrat pairs, we used the SIMPER method described by Clarke (1993). We used the average contribution of each taxa to the overall dissimilarity between sets of samples, $\bar{\delta}_{j}$, and the standard deviation of this contribution. $\mathrm{SD}\left(\delta_{1}\right)$. We used the ratio of mean-to-SD as a statistic $\overline{\delta_{i}} / \mathrm{SD}\left(\delta_{i}\right)$ to evaluate the contribution of each taxa to the dissimilarity between pairs of samples. We used as an arbitrarily defined cutoff a mean-to-SD ratio of 2 .

We then analysed the reduced and constrained datasets to examine whether patterns were maintained as shoot density was constrained. This was done in 2 main ways. Firstly, we used 2 -way nested ANOSIM to test differences between locations and among quadrats for each dataset. The focus of this was to see if the patterns of significant differences were maintained. We then used Mantel tests (Mantel 1967) to examine the degree of correspondence between the patterns expressed by each of the 5 constrained datasets (i.e. those with the number of shoots constrained to 3) with those of the reduced dataset (i.e. with the number of shoots unconstrained). In these tests, Bray-Curtis dissimilarity matrices were correlated (Pearson's product moment correlation coefficient), and then one repeatedly permuted, with correlations carried out after each permutation. We generated 1000 permutations for each test. In this way, the significance of the correlation between the 2 dissimilarity matrices could be examined: the proportion of correlations from the randomisation distribution higher than the original yielded the significance level (Manly 1997).

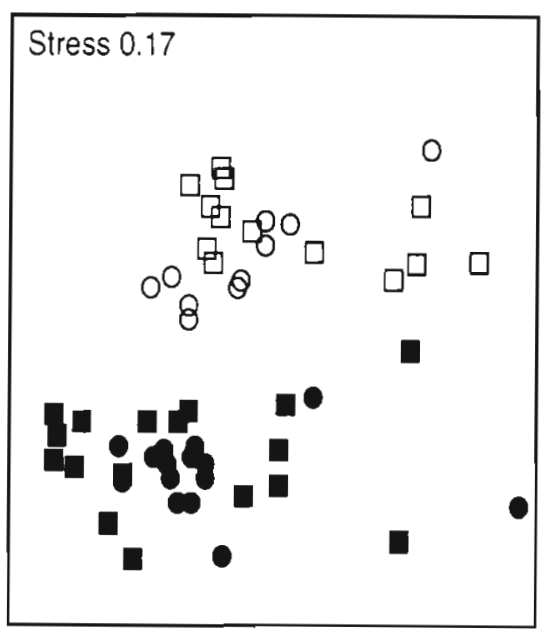

Fig. 2. Semi-Strong Hybrid multidimensional scaling ordination of all subquadrats, constructed in 2 dimensions from Bray-Curtis dissimilarities using presence/absence data. $(\square, 0)$ West locations; $(O, \square)$ east locations. Samples from the 2 regions cluster separately 


\section{RESULTS}

\section{Spatial patterns}

The SSH ordination showed a clear separation of samples taken from the eastern and western regions (Fig. 2). This was reflected by high dissimilarities among samples taken from different regions relative to dissimilarities at other spatial scales (Fig. 3). There was little difference between the mean dissimilarity of samples taken from different locations within a region and the mean dissimilarity of samples taken from different quadrats within a location. Samples taken from the same quadrat showed the lowest mean dissimilarity (and thus were relatively similar in species composition: Fig. 3).

For each region, 2-way nested ANOSIM tests yielded significant differences among quadrats (Table 1). This indicates that there were significant differences among sets of samples separated by $<10 \mathrm{~m}$. In contrast, the tests showed no significant differences between the 2 locations for either region (Table 1).

Multiple comparisons (conducted using 1-way ANOSIM) for each of the 4 locations gave some indication of which quadrats had significantly different assemblages (Table 2) Because of the exclusion of subquadrats which fell on bare sand, the number of permutations in each case was low (ranging from 4 to 35); we considered only pairwise comparisons with the maximum number of permutations available (35). (At best, this allowed rejection of the null hypothesis of no

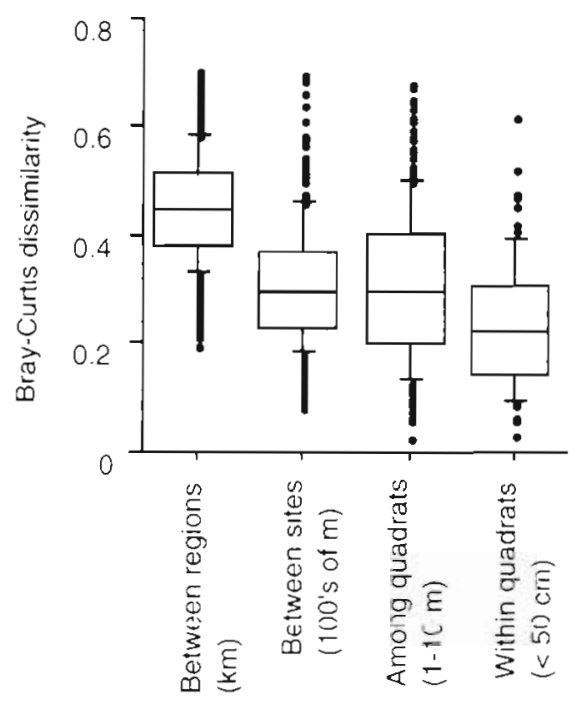

Fig. 3. Box plots for Bray-Curtis dissimiarities at each level of the spatial hierarchy. Dissimilarity was greatest at the scale of kilometres, and there was little difference in dissimilarities at the scales of hundreds or tens of metres
Table 1. Results of 2-way nested ANOSIM tests examining differences between locations, and among quadrats within locations. Tests were conducted separately for each region

\begin{tabular}{|lccc|}
\hline $\begin{array}{l}\text { Region } \\
\text { Factor }\end{array}$ & $\begin{array}{c}\text { No. of per- } \\
\text { mutations }\end{array}$ & Clarke's R & $\begin{array}{c}\text { Significance } \\
(\%)\end{array}$ \\
\hline West & & & \\
Location & 126 & -0.013 & 49.2 \\
Quadrat (Location) & 10000 & 0.214 & 0.3 \\
East & & & \\
Location & 56 & -0.026 & 51.8 \\
Quadrat (Location) & 10000 & 0.327 & 0.2 \\
\hline
\end{tabular}

difference at a $p<2.9 \%$ level. Rejection of the null hypothesis could be made at a $\mathrm{p}<5 \%$ level.) Corrections were not made for multiple testing. Multiple comparisons showed that both of the locations in the west region, and one of the locations in the east region, had pairs of quadrats that were significantly different (Table 2). Only comparisons yielding Clarke's R greater than 0.5 resulted in significant differences.

Mean shoot density among quadrats was quite variable in each location (Fig. 4). The significant differences in species composition between pairs of quadrats appeared to be related to differences in shoot

Table 2. Results of multiple comparison tests (generated using 1-way ANOSIM conducted for each location) examining pairwise differences among quadrats within each location. NS = not significant; "significant at $p<2.9 \% ;-=$ excluded because the number of permutations $<35$

\begin{tabular}{|c|c|c|c|c|}
\hline & \multicolumn{4}{|c|}{ Quadrat } \\
\hline & 1 & 2 & 3 & 4 \\
\hline \multicolumn{5}{|l|}{ West } \\
\hline \multicolumn{5}{|l|}{ Location 1} \\
\hline 2 & $0.694^{\circ}$ & & & \\
\hline 3 & $-0.213^{\mathrm{NS}}$ & - & & \\
\hline 4 & $-0.296^{\mathrm{Ns}}$ & - & & - \\
\hline 5 & $0016^{\mathrm{NS}}$ & $0.944^{\circ}$ & $0.352^{\mathrm{N} 5}$ & $0.074^{\mathrm{NS}}$ \\
\hline \multicolumn{5}{|l|}{ Location 2} \\
\hline 2 & $0.333^{\mathrm{NS}}$ & & & \\
\hline 3 & - & - & & \\
\hline 4 & $-0.065^{\mathrm{NS}}$ & $-0.093^{\mathrm{NS}}$ & - & \\
\hline 5 & $0.260^{\mathrm{NS}}$ & $0.536^{\circ}$ & - & $0.315^{\mathrm{NS}}$ \\
\hline \multicolumn{5}{|l|}{ East } \\
\hline \multicolumn{5}{|l|}{ Location 1} \\
\hline 2 & - & & & \\
\hline 3 & $-0.357^{\mathrm{NS}}$ & $0.852^{\circ}$ & & \\
\hline$\dot{4}$ & - & - & $-0.111^{N C}$ & \\
\hline 5 & - & - & - & - \\
\hline \multicolumn{5}{|l|}{ Location 2} \\
\hline 2 & $-0.019^{\mathrm{NS}}$ & & & \\
\hline 3 & - & $0.444^{\mathrm{NS}}$ & & \\
\hline 4 & - & -. & - & \\
\hline 5 & - & - & - & - \\
\hline
\end{tabular}




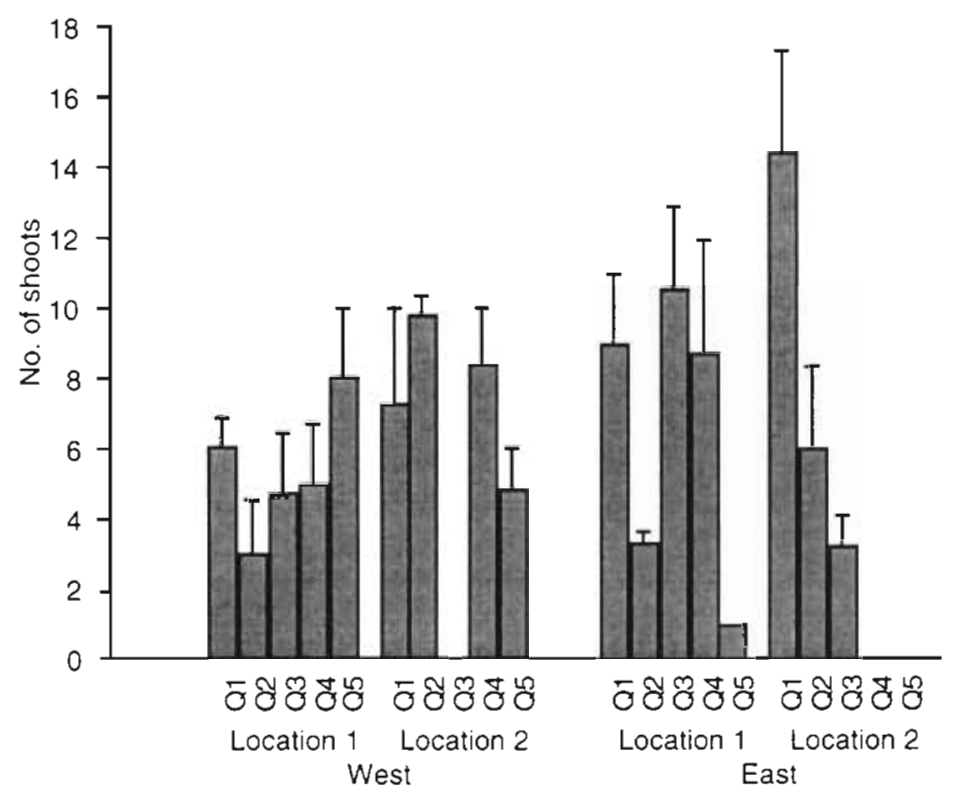

Fig. 4. Mean shoot densities (+ standard errors) within each quadrat. $\mathrm{Q}=$ Quadrat cantly different in the multiple comparison tests (Table 3). For those that did, this appeared to be because they were absent from quadrats with low shoot densities. Only 1 taxon (Champia viridis) yielded high meanto-SD ratios for more than 1 location. The taxa also represented a range of different types of macroalgae, including small erect red algae (Ceramium shepherdii, Herposiphonia secunda, Champia vindis, Aglaothamnion sp.), an articulated coralline alga (Metagoniolithon steliferum), a foliose brown alga (Dictyota sp.) and a filamentous brown alga (Feldmannia irregularis). This suggests that the processes structuring small-scale patterns were not influencing just 1 particular type of algae. No species yielded mean-to-SD ratios above 2 for comparisons between locations within each region, indicating that species were generally evenly distributed within a region.

\section{Analyses of constrained data}

density. Generally, quadrat pairs in each location that had very different mean shoot densities yielded high Clarke's R (Fig. 5, Table 2). The trend for higher Clarke's $\mathrm{R}$ with larger differences in mean shoot density is evident, but the presence of an outlier rendered the correlation relatively low $\left(r^{2}=0.289\right)$.

\section{Species analyses}

Relatively few species yielded mean-to-SD ratios $\left[\delta_{j} / \mathrm{SD}\left(\delta_{1}\right)\right]$ above 2 for quadrats shown to be signifi-

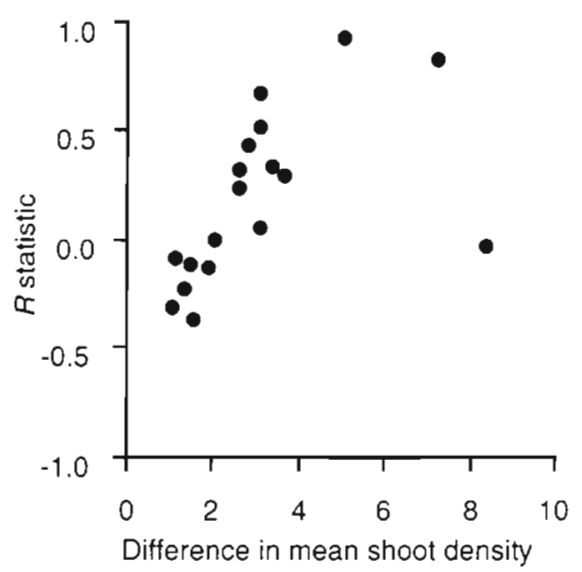

Fig. 5. Relationship between Clarke's R yielded by multiple comparison tests (from Table 2) and differences in mean shoot density for quadrat pairs
Analyses of the constrained data were aimed at determining whether overall patterns, and significant differences among quadrats, were maintained if shoot density was constant. This was to control for the possibility that patchiness was simply due to a speciesarea function, i.e. a higher density of shoots would provide more substrate and thus would be expected to have more species. Before analysing the constrained data, it was first necessary to determine whether the reduced dataset (i.e. the dataset with the number of shoots in each sample unconstrained, but excluding samples with $<3$ shoots) reflected the same patterns as the original data.

Analysis of data for the eastern region yielded slightly different results between the reduced dataset and the original dataset. The reduced dataset yielded significant differences between locations and among quadrats, unlike the original dataset, in which locations were not significantly different (Tables 1 \& 4). Analysis of data for the western region yielded similar results for the original data and the reduced dataset. Both yielded no significant difference between locations and significant differences between quadrats (Tables $1 \& 4$ ).

ANOSIM tests on the 5 constrained datasets yielded varying results, but some patterns were maintained. For the western region, locations were never significantly different, and quadrats were significantly different in 2 of 5 cases. For the eastern region, locations were significantly different in 1 of 5 cases, and quad- 
Table 3. Epiphyte taxa that yielded mean-to-SD ratios $\left[\delta_{1} / \mathrm{SD}\left(\delta_{j}\right)\right]$ above 2 in SIMPER tests, thus contributing strongly to pairwise similarities among quadrats shown to be significantly different in Table 2 (indicated by asterisks). The mean proportion of shoots each species was recorded on is given for each quadrat. $-=$ most samples fell on bare sand, so excluded from analyses

\begin{tabular}{|c|c|c|c|c|c|}
\hline \multicolumn{3}{|l|}{$\begin{array}{l}\text { Location } \\
\text { Epiphyte species }\end{array}$} & \multicolumn{3}{|c|}{ Quadrat } \\
\hline West Location 1 & & & & & \\
\hline (total no. of taxa $=41$ ) & $13^{\circ}$ & $\begin{array}{l}2 \cdots \\
0.00\end{array}$ & $\begin{array}{c}3 \\
2083\end{array}$ & $\begin{array}{c}4 \\
30.00\end{array}$ & $\begin{array}{c}5^{\circ} \\
28.81\end{array}$ \\
\hline $\begin{array}{l}\text { Ceramium sheperdil } \\
\text { Champia viridis }\end{array}$ & $\begin{array}{l}13.13 \\
34.65\end{array}$ & 0.00 & $\begin{array}{l}20.83 \\
25.00\end{array}$ & 28.33 & $\begin{array}{l}28.01 \\
7.15\end{array}$ \\
\hline Dictyota sp. 1 & 22.95 & 0.00 & 16.67 & 4.17 & 17.50 \\
\hline Herposiphonia secunda & 56.61 & 0.00 & 54.17 & 28.33 & 25.83 \\
\hline Metagoniolithon steliferum & 11.25 & 0.00 & 8.33 & 4.17 & 23.10 \\
\hline $\begin{array}{l}\text { West Location } 2 \\
\text { (total no. of taxa }=24 \text { ) } \\
\text { Champia viridis }\end{array}$ & $\begin{array}{c}1 \\
18.97\end{array}$ & $\begin{array}{c}2^{\bullet} \\
22.22\end{array}$ & $\begin{array}{l}3 \\
-\end{array}$ & $\begin{array}{c}4 \\
33.33\end{array}$ & $\begin{array}{c}5 \\
0.00\end{array}$ \\
\hline $\begin{array}{l}\text { East Location } 1 \\
\text { (total no. of taxa }=28 \text { ) } \\
\text { Aglaothamnion sp. } 1 \\
\text { Feldmannia irregularis }\end{array}$ & $\begin{array}{c}1 \\
27.92 \\
64.94\end{array}$ & $\begin{array}{l}2 \cdot \\
0.00 \\
0.00\end{array}$ & $\begin{array}{c}3 \\
35.36 \\
83.81\end{array}$ & $\begin{array}{c}4 \\
24.84 \\
91.67\end{array}$ & $\begin{array}{c}5 \\
0.00 \\
0.00\end{array}$ \\
\hline
\end{tabular}

tion. At the next scale down our hierarchy, locations and quadrats yielded dissimilarities that were about the same. Within quadrats, dissimilarities were comparatively low, indicating that samples collected within $50 \mathrm{~cm}$ of each other were relatively homogeneous. In this study, we homogenised patterns that may have been present at even smaller scales, such as the distribution of individual epiphytes among shoots or even over a single shoot.

Patterns in species compositions were thus evident at 2 of the spatial scales we examined: between regions separated by $2 \mathrm{~km}$ (the largest spatial scale examined), and among sets of samples separated by metres (i.e. among quadrats). Variation at the scale of metres remained the dominant pattern at hundreds of metres: if there was any 'gradient' in species compositions rats were significantly different in all cases (Table 4). Overall, the pattern of no significant differences between locations was maintained. The pattern of significant differences among quadrats was maintained for the eastern region, but there were some deviations from this pattern in the western region.

Mantel tests were conducted to determine whether the underlying dissimilarities of the 5 constrained datasets followed the same patterns as those of the unconstrained, reduced dataset. Results indicated that the dissimilarity matrices for all 5 constrained datasets were significantly correlated with the dissimilarity matrix for the reduced dataset (Table 5). Correlations were above 0.73 in all cases, and no permutations resulted in correlations higher than the original (Table 5), indicating that overall patterns were maintained even when the number of shoots per sample was constrained.

\section{DISCUSSION}

Epiphyte assemblages showed a hierarchy of differences in species compositions at different spatial scales. At the scale of kilometres, samples from different regions were least similar in composition, and grouped apart in the ordina-
Table 4. Results of 2-way nested ANOSIM tests, examining differences between locations, and among quadrats within locations, for the reduced and constrained datasets (reduced datasets have the same data as the original dataset, but exclude subquadrats with $<3$ shoots; constrained datasets contain 3 randomly selected shoots per subquadrat). As with the original data (Table 1), tests were conducted separately for each region

\begin{tabular}{|c|c|c|c|c|c|}
\hline Dataset & Region & Factor & $\begin{array}{c}\text { No. of } \\
\text { permutations }\end{array}$ & $\begin{array}{l}\text { Clarke's } \\
\mathrm{s} \quad \mathrm{R}\end{array}$ & $\begin{array}{l}\text { Signifi- } \\
\text { cance }(\%)\end{array}$ \\
\hline \multirow[t]{4}{*}{ Reduced dataset } & West & Location & 126 & -0.019 & 52.4 \\
\hline & & Quadrat (Location) & 10000 & 0.191 & 4.0 \\
\hline & East & Location & 35 & 0.296 & 2.9 \\
\hline & & Quadrat (Location) & 10000 & 0.348 & 1.0 \\
\hline \multirow[t]{4}{*}{ Constrained 1} & West & Location & 126 & 0.088 & 20.6 \\
\hline & & Quadrat (Location) & 10000 & 0.395 & 0.0 \\
\hline & East & Location & 35 & 0.259 & 5.7 \\
\hline & & Quadrat (Site) & 10000 & 0.402 & 0.3 \\
\hline \multirow[t]{4}{*}{ Constrained 2} & West & Location & 126 & -0.081 & 71.4 \\
\hline & & Quadrat (Location) & 10000 & 0.156 & 6.7 \\
\hline & East & Location & 35 & 0.333 & 5.7 \\
\hline & & Quadrat (Location) & 10000 & 0.300 & 1.5 \\
\hline \multirow[t]{4}{*}{ Constrained 3} & West & Location & 126 & -0.031 & 57.1 \\
\hline & & Quadrat (Location) & 10000 & 0.116 & 12.3 \\
\hline & East & Location & 35 & 0.148 & 20.0 \\
\hline & & Quadrat (Location) & 10000 & 0.589 & 0.0 \\
\hline \multirow[t]{4}{*}{ Constrained 4} & West & Location & 126 & -0.006 & 51.6 \\
\hline & & Quadrat (Location) & 10000 & 0.205 & 2.8 \\
\hline & East & Location & 35 & 0.500 & 2.9 \\
\hline & & Quadrat (Location) & 10000 & 0.281 & 2.6 \\
\hline \multirow[t]{4}{*}{ Constrained 5} & West & Location & 126 & 0.162 & 11.1 \\
\hline & & Quadrat (Location) & 10000 & 0.049 & 31.3 \\
\hline & East & Location & 35 & 0.148 & 20.0 \\
\hline & & Quadrat (Location) & 10000 & 0.545 & 0.0 \\
\hline
\end{tabular}


Table 5. Results of Mantel tests examining the correlation between the Bray-Curtis dissimilarity matrices of the constrained datasets against the reduced (unconstrained) data

\begin{tabular}{|lcl|}
\hline Constrained dataset no. & $\mathrm{r}^{2}$ & Significance \\
\hline 1 & 0.817 & $\mathrm{p}<0.001$ \\
2 & 0.736 & $\mathrm{p}<0.001$ \\
3 & 0.787 & $\mathrm{p}<0.001$ \\
4 & 0.823 & $\mathrm{p}<0.001$ \\
5 & 0.755 & $\mathrm{p}<0.001$ \\
\hline
\end{tabular}

these patches seemed to be due to the absence (rather than the presence) of certain taxa: SIMPER analyses indicated that taxa discriminating between sets of samples were absent from patches with low seagrass density. This indicates that at least some epiphyte taxa responded to structuring influences at small spatial scales.

\section{Potential structuring processes}

Hierarchies of spatial pattern such as this reflect the operation of different processes at different scales (O'Neill et al. 1991, Farnsworth \& Ellison 1996). Processes that may lead to differences in species compositions of epiphytes over several kilometres are likely to be processes with broad spatial extent. On Success Bank, such factors may include gradients in wave exposure and shelf-scale hydrodynamics. An additional possibility is the influence of water flowing from the nearby Swan River (see Fig. 1).

Processes that are likely to lead to differences at the scale of metres may include variations in habitat availability, grazing pressure, local hydrodynamic flows, restricted dispersal of propagules and the influence of established assemblages on potential recruitment. Patterns of aggregation at the scale of metres or less have been observed in a range of benthic marine ecosystems, such as soft sediments (see references in Barry \& Dayton 1991) and reefs (Reichelt \& Bradbury 1984, Yoshioka \& Yoshioka 1989). Experiments in soft sediment ecosystems suggest that both physical processes (e.g. hydrodynamics) and biological processes (e.g. predation, competition) may cause such small-scale patchiness (Thrush 1991).

In our study, one influence on patchiness at the scale of metres appeared to be shoot density within patches: pairs of quadrats with significantly different assemblages had large differences in mean shoot density. Potentially, this could be due to a species-area mechanism. That is, patches with a high shoot density have more available substrate (seagrass leaves) for epiphyte colonisation, so could have more species. However, data manipulation to constrain datasets to a consistent shoot density ( 3 shoots sample $e^{-1}$ ) yielded similar results to the unconstrained data. In other words, although the number of shoots per sample was kept equal, the pattern of significant patchiness at the scale of metres was generally maintained. This suggests that, if differences in species compositions were due to variation in shoot density, it was not entirely due to a species-area mechanism.

If this is true, then variation in shoot density may have some indirect influence. A number of mechanisms could explain how shoot density may indirectly influence species compositions of epiphyte assemblages. One likely explanation is alteration of smallscale hydrodynamic features that may in turn affect settlement of propagules, particularly as many algal propagules have limited dispersal ranges. Aggregation in the distribution of the propagules and adults of epilithic algae is common, and seems to be partly related to limited dispersal ranges (Rice 1987, Kendrick \& Walker 1995). Although propagule size and duration of viability -2 key features in propagule dispersalvary considerably, propagules of most species sink to the substrate quickly (Hoffman 1987).

If variation in seagrass shoot density affects water movement, this may help maintain aggregations of epiphytic algae. Attenuation of wave energy in seagrass beds is an established phenomenon, with areas of higher shoot density reducing energy the most (Eckman 1987). Seagrass (particularly heavily epiphytised seagrass) may also generate small-scale turbulence (Koch 1996) that may also influence propagule dispersal. Dayton \& Tegner (1984) described how altered flow regimes within kelp beds retarded dispersal of organisms with short larval phases. Potentially, reduced energy and increased small-scale turbulence in Posidinia coriacea beds could restrict dispersal of propagules of epiphytic algae, leading to aggregation of propagules at small scales. Reduced energy within dense seagrass could also lead to reduced scouring, allowing settled propagules to remain, leading to aggregation of adults

It is easy to envisage how such mechanisms may promote aggregations in populations of individual species. As species may have different scales of response (Kotliar \& Wiens 1990, Levin 1992), patterns in multispecies assemblages may be complex. The results of our study suggest that the structure of assemblages of epiphytic algae may be influenced by several species with similar scales of response.

\section{Lessons for designing studies of epiphyte assemblages}

Patchiness at the scale of metres will influence the design of comparative and experimental studies of epi- 
phyte assemblages. Such patchiness will directly effect variability and statistical power in comparative studies examining patterns over large spatial scales (i.e. kilometres or more). In such studies, researchers aiming to detect the large-scale patterns would generally prefer to gather precise estimates with a minimum of amongreplicate variation. This may be done in 2 main ways: by using a few large sample units containing several patches, or by using many small sample units that cover only a proportion of each patch. Our results suggest that large sampling units which would homogenise patchiness in epiphyte assemblages are likely to require an area of several square metres. Examination of the epiphytes on all shoots within an area of several square metres is an impossible task due to time and cost constraints, and is unnecessary. Using the second approach, studies can be designed in such a way that the variability among samples that results from small-scale patchiness is taken into account. As Morrisey et al. (1992) point out, patchiness at small spatial scales may also reduce the power of statistical tests, and this should be taken into account when designing sampling programs.

Another important consideration is that samples may need to be collected over an area of more than just a few metres. By doing so, a range of patches will be sampled and the true variability of the overall location may be reflected. If samples are not sufficiently separated, they may not sample from different patches, and therefore may not yield true estimates of variability, which may in turn confound comparisons.

Patchiness at the scale of metres will also influence the results of experimental studies of processes structuring epiphyte assemblages. In such studies, patchiness at the scale of metres may lead to conclusions that have limited applicability if the design does not include a range of patches. Differences in species composition that we detected at the scale of metres may influence (and be influenced by) processes such as grazing and recruitment. To reach more general conclusions, experiments should encompass a range of patches. Of course, differences in the operation of these processes may occur at larger spatial scales, and these should also be considered (Underwood 1998).

Our results were obtained from a seagrass with a clumping growth habit, adapted to areas of relatively high wave energy. The scales of spatial variability in epiphyte assemblages growing on other seagrasses, unid in other areas, nieed to be exuminined before broad conclusions can be drawn. However, there is some indication that small-scale patchiness may also occur in other seagrasses. For example, Kendrick \& Burt (1997) suggested that the epiphytes growing on Posidonia sinuosa demonstrated small-scale patchiness in species compositions, based on the degree of variabil- ity among replicates. Similarly, Jernakoff \& Nielsen (1998) found considerable among-replicate variation in the biomass of epiphytes growing on $P$. sinuosa and Amphibolis griffithii.

Our conclusions are based on 1 sampling event. A study comprising a longer time period would reveal how consistent the spatial hierarchies are over time. This may be an important consideration as it is conceivable that the degrees of dissimilarity at different levels of the spatial hierarchy change seasonally or annually.

Small-scale patchiness is also probably not restricted to species compositions-biomass, nutrient content, productivity and other variables might also show patchiness at similar scales. Researchers examining patterns in epiphyte assemblages, or the ecological functions of epiphytes at larger spatial scales, clearly need to be aware of the potential for small-scale patchiness, and the influence this may have on variability in their data.

Acknowledgements. M. Westera assisted with the processing of samples. G. Kendrick and P. Jernakoff provided comments on a draft of this manuscript. J. Huisman's expertise in identifying the macroalgal epiphytes was invaluable. Thanks to all for their willing help. The work was funded by Cockburn Cement Ltd.

\section{LITERATURE CITED}

Andrew NL, Mapstone BD (1987) Sampling and the description of spatial pattern in marine ecology. Oceanogr Mar Biol Annu Rev 25:39-90

Barry JP, Dayton PK (1991) Physical heterogeneity and the organisation of marine communities. In: Kolasa J, Pickett STA (eds) Ecological heterogeneity. Springer-Verlag, New York, p 270-320

Belbin L (1991) Semi-strong hybrid scaling, a new ordination algorithm. J Veg Sci 2:491-496

Bray JR, Curtis JT (1957) An ordination of the upland forest communities of southern Wisconsin. Ecol Monogr 2?: $325-349$

Cambridge ML., Chiffings AW, Brittan C, Moore L, McComb AJ (1986) The loss of seagrass in Cockburn Sound, Western Australıa. II. Possible causes of seagrass decline. Aquat Bot 24:269-285

Clarke KR (1993) Non-parametric multivariate analyses of change in community structure. Aust J Ecol 18:117-143

Clarke KR, Green RH (1988) Statistical design and analysis for a 'biological effects' study. Mar Ecol Prog Ser 46: $213-226$

Coleman VL, Burkholder JM (1994) Community structure and productivity of epiphytic microalgae on eelgrass (Zostera Marina L.) under water-column nitrate enrichment. J Exp Mar Biol Ecol 179:29-48

Dayton PK, Tegner MJ (1984) The importance of scale in community ecology: a kelp forest example with terrestrial analogs. In: Price PW, Slobodchikoff CN, Gaud WS (eds) A new ecology: novel approaches to interactive systems. John Wiley \& Sons, New York, p 457-481 
Eckman JE (1987) The role of hydrodynamics in recruitment growth, and survival of Argopecten irradians (L.) and Anomia simplex (D'Orbigny) within eelgrass meadows. J Exp Mar Biol Ecol 106:165-191

Farnsworth EJ, Ellison AM (1996) Scale-dependent spatial and temporal variability in biogeography of mangrove root epibiont communities. Ecol Monogr 66:45-66

Fry B (1984) 13C/12C ratios and the trophic importance of algae in Florida Syringodium filiforme seagrass meadows. Mar Biol 79:11-19

Goering JJ, Parker PL (1972) Nitrogen fixation by epiphytes on seagrass. Limnol Oceanogr 17:320-323

Hewitt JE, Thrush SF, Cummings VJ, Turner SJ (1998) The effect of changing sampling scales on our ability to detect effects of large-scale processes on communities. J Exp Mar Biol Ecol 227:251-264

Hoffman AJ (1987) The arrival of seaweed propagules at the shore: a review. Bot Mar 30:151-165

Jernakoff $P$, Nielsen J (1998) Plant-animal associations in two species of seagrasses in Western Australia. Aquat Bot 60: $359-376$

Jernakoff P, Brearley A, Nielsen J (1996) Factors affecting grazer-epiphyte interactions in temperate seagrass meadows. Oceanogr Mar Biol Annu Rev 34:109-162

Kendrick GA, Burt JS (1997) Seasonal changes in epiphytic macro-algae assemblages between offshore exposed and inshore protected Posidonia sinuosa Cambridge et Kuo seagrass meadows, Western Australia. Bot Mar 40:77-85

Kendrick GA, Walker DI (1995) Dispersal of propagules of Sargassum spp. (Sargassaceae: Phaeophyta): observations of local patterns of dispersal and consequences for recruitment and population structure. J Exp Mar Biol Ecol 192: $273-288$

Klumpp DW, Salita-Espinosa JS, Fortes MD (1992) The role of epiphytic periphyton and macroinvertebrate grazers in the trophic flux of a tropical seagrass community. Aquat Bot 43:327-349

Koch EW (1996) Hydrodynamics of a shallow Thalassia testudinum bed in Florida, USA. In: Kuo $\mathrm{J}$, Phillips RC, Walker DI, Kirkman $H$ (eds) Seagrass biology: proceedings of an international workshop. The University of Western Australia, Nedlands, p 105-110

Kotliar NB, Wiens JA (1990) Multiple scales of patchiness and patch structure: a hierarchical framework for the study of heterogeneity. Oikos 59:253-260

Kuo J, Cambridge ML (1984) A taxonomic study of the Posidonia ostenfeldii complex (Posidoniaceae) with description of four new Australian seagrasses. Aquat Bot 20: 267-295

Levin SA (1992) The problem of pattern and scale in ecology. Ecology 73:1943-1967

Lin HJ, Nixon SW, Taylor DI, Granger SL, Buckley BA (1996)

Editorial responsibility: Otto Kinne (Editor),

Oldendorf/Luhe, Germany
Responses of epiphytes on eelgrass, Zostera marina L., to separate and combined nitrogen and phosphorus enrichment. Aquat Bot 52:243-258

Manly BFJ (1997) Randomization, bootstrap and Monte Carlo methods in biology, 2nd edn. Chapman \& Hall, London

Mantel N (1967) The detection of disease clustering and a generalised regression approach. Cancer Res 27:209-220

Morgan MD, Kitting CL (1984) Productivity and utilization of the seagrass Halodule wrightii and its attached epiphytes. Limnol Oceanogr 29:1066-1076

Morrisey DJ, Howitt L, Underwood AJ, Stark JS (1992) Spatial variation in soft-sediment benthos. Mar Ecol Prog Ser 81: 197-204

O'Neill RV, Gardner RH, Milne BT, Turner MG, Jackson B (1991) Heterogeneity and spatial hierarchies. In: Kolasa J, Pickett STA (eds) Ecological heterogeneity. Springer-Verlag, New York, p 85-96

Penhale PA (1977) Macrophyte-epiphyte biomass and productivity in an eelgrass (Zostera marina L.) community. J Exp Mar Biol Ecol 26:211-224

Reichelt RE, Bradbury RH (1984) Spatial patterns in coral reef benthos: multiscale analysis of sites from three oceans. Mar Ecol Prog Ser 17:251-257

Rice EL (1987) Small-scale distributional pattern in Xiphophora gladiata (Labillardiere) Montagne ex Kjellman (Fucales, Phaeophyta). Phycologia 26:247-251

Silberstein K, Chiffings AW, McComb AJ (1986) The loss of seagrass in Cockburn Sound, Western Australia. III. The effect of epiphytes on productivity of Posidonia australis Hook. F. Aquat Bot 24:355-371

Thrush SF (1991) Spatial patterns in soft-bottom communities. Trends Ecol Evol 6:75-79

Underwood AJ (1998) Design, implementation and analysis of ecological and environmental experiments: pitfalls in the maintenance of logical structures. In: Resetarits WJJ, Bernardo $J$ (eds) Experimental ecology: issues and perspectives. Oxford University Press, New York, p 325-349

Underwood AJ, Chapman MG (1998) A method for analysing spatial scales of variation in composition of assemblages. Oecologia 117:570-578

Walker DI, Woelkering WJ (1988) A quantitative study of sediment contributions by epiphytic coralline algae in seagrass meadows in Shark bay, Western Australia. Mar Ecol Prog Ser 43:71-77

Wilmotte A, Demoulin V (1988) Studies of marine epiphytic algae, Calvi, Corsica. Il. Seasonal variations in the populations of epiphytic blue-green algae in three harbours with different pollution loads. Br Phycol J 23:259-266

Yoshioka PM, Yoshioka BB (1989) A multispecies, multiscale analysis of spatial pattern and its application to a shallowwater gorgonian community. Mar Ecol Prog Ser 54 $257-264$

Submitted: March 5, 1999; Accepted: August 2, 1999

Proofs received from author(s): December 27, 1999 